\title{
LAYANAN LIBRARY AND KNOWLEDGE CENTER (LKC) BINA NUSANTARA UNIVERSITY DI ERA PANDEMI COVID-19
}

\author{
Syifa Naufal Qisty \\ Pusat Data dan Dokumentasi Ilmiah LIPI \\ Magister Ilmu Komunikasi Universitas Padjadjaran \\ syifa20018@mail.unpad.ac.id \\ Ninis Agustini Damayani \\ Magister Ilmu Komunikasi Universitas Padjadjaran \\ ninis.agustini@unpad.ac.id \\ Elnovani Lusiana \\ Magister Ilmu Komunikasi Universitas Padjadjaran \\ elnovani.lusiana@unpad.ac.id

\section{Ilham Gemiharto} \\ Magister Ilmu Komunikasi Universitas Padjadjaran \\ ilham@unpad.ac.id

\section{Ute Lies Siti Khadijah} \\ Magister Ilmu Komunikasi Universitas Padjadjaran \\ ute.lies@unpad.ac.id
}

Received : 18 June 2021 Revised : 09 July 2021 Accepted : 20 September 2021 DOI :

\begin{abstract}
The covid-19 pandemic has succeeded in changing the order of life, one of which is in the field of libraries. This also changes the services carried out in the BINUS University library. The BINUS University Library has made several adjustments to some of its services. Services that are usually done in person and face-to-face are now done online. This online service is also an example of using computers as a medium for communication. This computer-mediated communication is reflected in several services and innovations carried out by the BINUS University library. This article aims to describe the services and innovations carried out by the BINUS University library. The method used is direct interview and literature study. The services provided by the BINUS University library are asynchronous, that is, they are carried out in a different time and space, and synchronous, that is, they are carried out in the same time and space. The results of the study show that several services and innovations have been carried out, such as reference clinics, cross-service services, document provision, and plagiarism checking, which are now also carried out online. Circulation services in the form of a book delivery system have also been improved during the pandemic. The BINUS University library has also made several innovations in its services in the pandemic era. These innovations include the payment of fines through Go-Pay and QRIS BCA, a virtual tour library service, and libtalks.
\end{abstract}

Keywords: library services; covid-19; BINUS University

\section{PENDAHULUAN}

Semenjak China pertama kali melaporkan adanya casus Covid-19 kepada World Health Organization (WHO) di bulan Desember 2019, Covid-19 telah menjadi pandemi di 
seluruh dunia dengan jumlah kasus terkonfirmasi mencapai 162.773.940 dengan jumlah kematian mencapai 3.375.573 dan terjadi di 235 negara. (WHO, 2021). Di Indonesia, kasus Covid-19 yang terkonfirmasi mencapai 1.739.750 dengan jumlah kematian mencapai 48.093 (WHO, 2021). WHO telah menyatakan keadaan pandemi sejak Maret 2020 dan semenjak itu pula telah banyak dilakukan pencegahan guna mengurangi resiko terpapar Covid-19.

Wabah covid-19 telah mengubah tatanan kehidupan masyarakat dunia. Banyak sektor yang kemudian berubah, mulai dari ekonomi, sosial, dan pendidikan. Dengan adanya wabah ini, masyarakat diimbau untuk melakukan social distancing, dimana masyarakat harus menjaga jarak satu sama lain. Selain itu, dengan adanya covid-19, mengakibatkan masyarakat harus melakukan pekerjaan dari rumah (work from home). Hampir semua kegiatan masyarakat dilakukan di rumah, mulai dari bekerja, beribadah, dan sekolah. Masyarakat diimbau untuk keluar rumah saat situasi mendesak saja. Masyarakat tidak lagi keluar rumah untuk berwisata, berkumpul, atau berbelanja.

Seiring berjalannya waktu, kini masyarakat diperkenankan kembali melakukan kegiatannya namun dengan memerhatikan protokol kesehatan yang terdiri dari 5M, yaitu Menjaga jarak; Memakai masker; Mencuci tangan menggunakan sabun dan air mengalir; Menghindari kerumunan; dan Membatasi mobilitas dan interaksi. Protokol kesehatan ini dilakukan sebagai bagian dari upaya pencegahan covid-19.

Demi mempertahankan eksistensinya di tengah pandemi covid, banyak cara yang dilakukan organisasi dan lembaga di dunia, salah satunya adalah dengan memaksimalkan kegiatan dalam bentuk digital. Hal ini pun dilakukan oleh perpustakaan. Menurut International Federation of Library Association (IFLA, 2020), terdapat beberapa penyesuaian yang dilakukan perpustakaan di seluruh dunia. Di beberapa negara, dimana kasus covid telah dibatasi dan pemerintahnya tidak mengambil tindakan khusus terhadap kasus covid, perpustakaan tetap buka dengan menerapkan beberapa protokol kesehatan, seperti: (1) memastikan akses ke sabun dan tempat cuci tangan, (2) menyediakan cairan antiseptic pencuci tangan, (3) menjaga permukaan benda-benda yang ada di perpustakaan tetap bersih, (4) memastikan untuk tidak mempekerjakan staff yang sedang sakit, (5) menyediakan laman dengan tautan ke informasi yang berguna di situs web mereka, dan (6) mempromosikan literasi media guna menghindari potensi kesalahan informasi online.

Di negara yang memiliki banyak kasus covid dimana pemerintahnya membatasi acara yang lebih besar dan secara aktif mendorong masyarakatnya untuk mengambil tindakan ekstra dalam kebersihan, beberapa batasan dilakukan di perpustakaan. Beberapa batasan itu diantaranya (1) mempertimbangkan kembali program perpustakaan seperti layanan 
storytelling atau lokakarya, terutama untuk pengguna beresiko, (2) melakukan upaya tambahan untuk memastikan kebersihan di seluruh area perpustakaan, (3) menghapus barang-barang beresiko seperti mainan atau headset dari peredaran, (4) mempertimbangkan untuk menutup study space di perpustakaan, serta (5) mempersiapkan potensi pembatasan lebih lanjut seperti memastikan staffnya untuk melakukan layanan perpustakaan secara digital.

Selain itu, terdapat pula layanan minimal yang diberikan oleh perpustakaan yang negaranya melakkan pembatasan lebih ketat pada pertemuan publik dan penutupan di wilayah yang paling terkena dampak. Beberapa layanan minimal ini diantaranya adalah (1) melakukan penutupan layanan dan hanya menyediakan layanan meminjam atau mengembalikan buku di konter, (2) menerapkan kebijakan karantina pada buku yang dikembalikan, (3) menerapkan rencana untuk menyediakan layanan jarak jauh seperti eLending, eLearning, atau dukungan untuk pengajaran jarak jauh, dan (4) memungkinkan staff untuk bekerja dari jarak jauh.

Pada negara yang melakukan langkah-langkah paling ketat, perpustakaan terpaksa ditutup. Dalam hal ini, beberapa langkah dilakukan perpustakaan seperti (1) memastikan semua staf bekerja dari rumah kecuali benar-benar diperlukan, (2) pustakawan dipindahkan ke tugas lain di departemen lain di kotanya, (3) menyediakan komunikasi berkelanjutan dengan pengguna untuk menggunakan sumber daya atau layanan perpustakaan, (4) mempromosikan penggunaan perpustakaan digital dan alat lainnya, (5) menawarkan amnesti pada buku fisik yang dipinjam sekaligus meningkatkan jumlah ebook yang dapat dipinjam pengguna, dan (6) menyediakan ruang perpustakaan untuk kegiatan lain.

Di Indonesia, banyak perpustakaan yang akhirnya melakukan penutupan pada layanannya secara fisik ketika pandemi dimulai. Salah satu perpustakaan yang terdampak adalah perpustakaan perguruan tinggi. Perpustakaan perguruan tinggi adalah perpustakaan yang berada di perguruan tinggi yang memiliki fungsi menunjang perguruan tinggi dalam mencapai visi dan misinya sesuai dengan Tri Dharma Perguruan Tinggi, yaitu pendidikan, pengajaran, penelitian, dan pengabdian kepada masyarakat. (Suharso, Arifiyana, \& Wasdiana, 2020)

Di awal pandemi, perguruan tinggi menerapkan kegiatan pembelajaran dari rumah. Hal ini juga mengakibatkan staf melakukan kegiatan bekerja dari rumah, termasuk pustakawan. Layanan perpustakaan secara fisik ditutup dan banyak perpustakaan yang memanfaatkan layanan perpustakaan secara virtual. Dengan memanfaatkan media teknologi, kini perpustakaan dapat dengan mudah menggapai pemustakanya. 
Menurut Fatmawati (Fatmawati, 2015) kunjungan virtual pemustaka di perpustakaan kian banyak. Ketika pemustaka hanya membuka katalog online perpustakaan untuk melihat ketersediaan koleksi, sudah termasuk mengunjungi perpustakaan secara virtual. Ruang virtual ini menjadi salah satu contoh teknologi komunikasi yang termediasi komputer atau Computer Mediated Communication (CMC).

Holmes dalam Fatmawati menjelaskan perspektif CMC, yaitu komunikasi yang dimediasi komputer. Komunikasi yang dimediasi computer ini dapat terjadi dalam situasi dan kondisi ruang dan waktu yang sama (synchronous) atau berbeda (asynchronous). Pada situasi yang asynchronous, komunikasi terjadi melalui e-mail, bulletin boards forum, blog, social media website, atau youtube. Sedangkan situasi synchronous terjadi ketika pengguna melakukan video conference, instant messaging chat, atau melakukan panggilan telepon melalui internet.

Situasi pandemi covid-19 mengakibatkan beberapa perpustakaan harus melakukan transformasi bentuk komunikasi dengan pemustakanya. Jika dulu lebih banyak dilakukan secara tatap muka, kini harus lebih memanfaatkan penggunaan teknologi. Peran perpustakaan di mata pemustaka dapat lebih kuat dengan adanya komunikasi yang termediasi oleh teknologi ini.

Salah satu perpustakaan perguruan tinggi yang memnafaatkan teknologi dalam melakukan komunikasi dengan pemustakanya adalah perpustakaan Bina Nusantara University (Library and Knowledge Center BINUS University). BINUS University merupakan perguruan tinggi swasta yang berawal dari sebuah kursus komputer di Jakarta dan kini menjadi perguruan tinggi swasta terbaik se-Indonesia. (Webometrics, 2021) Oleh karenanya, artikel ini akan membahas bagaimana layanan yang dilakukan oleh Library and Knowledge Center (LKC) BINUS University dalam masa pandemi covid-19.

\section{METODE}

Penelitian ini dilakukan dengan menggunakan pendekatan kualitatif. Pendekatan kualitatif digunakan untuk menjabarkan kejadian sosial secara deskriptif dan spesifik, agar pembaca memahami hal-hal yang terjadi di luar kejadian yang bersifat umum. (Denzin \& Lincoln, 2018). Sebagaimana diungkapkan oleh Nasution dalam (Kurnia Firmansyah \& Dyah Putrisari, 2017), pendekatan kualitatif merupakan sebuah kegiatan pengamatan dalam lingkungan hidup, berinteraksi dengan mereka, kemudian berusaha memakai bahasa dan tafsiran mereka tentang dunia sekitarnya, dengan menggunakan metode ini akan 
menghasilkan data-data deskriptif berupa kata-kata tertulis atau lisan dari orang-orang dan perilaku yang diamati.

Metode yang digunakan adalah deskriptif kualitatif. Penelitian deskriptif seperti disebutkan oleh Nana Sudjana dan Ibrahim dalam (Margareta, 2013) merupakan penelitian yang berusaha mendeskripsikan suatu peristiwa dan kejadian yang terjadi pada saat sekarang dimana peneliti berusaha memotret peristiwa dan kejadian yang menjadi pusat perhatian untuk kemudian digambarkan sebagaimana adanya. Penelitian deskriptif ini bertujuan untuk menggambarkan secara tepat bagaimana sifat-sifat suatu gejala sosial, baik individu maupun kelompok dan keadaaan sosial tertentu.

Teknik pengumpulan data yang dilakukan adalah dengan melakukan wawancara kepada salah satu karyawan di BINUS dan studi pustaka. Hal ini dilakukan untuk mendapatkan data dari berbagai literatur seperti artikel ilmiah, makalah, buku, dan surat kabar.

\section{HASIL DAN PEMBAHASAN}

Undang-Undang No 2 tahun 1989 tentang Sistem Pendidikan Nasional menyebutkan salah satu syarat untuk menyelenggarakan perguruan tinggi adalah dengan memiliki perpustakaan. (Suharso et al., 2020) Menurut Peraturan Kepala Perpustakaan Nasional Republik Indonesia Nomor 13 tahun 2017 tentang Standar Nasional Perpustakaan Perguruan Tinggi, perpustakaan perguruan tinggi merupakan bagian integral dari kegiatan pendidikan, penelitian, dan pengabdian kepada masyarakat dan memiliki fungsi sebagai pusat sumber belajar untuk mendukung tercapainya tujuan pendidikan di perguruan tinggi. (Perpusnas, 2017) Keberadaan perpustakaan di perguruan tinggi memiliki tujuan: (1) menyediakan bahan perpustakaan dan akses informasi bagi pemustaka untuk kepentingan pendidikan, penelitian dan pengabdian kepada masyarakat; (2) mengembangkan, mengolah, dan mendayagunakan koleksi; (3) meningkatkan literasi informasi pemustaka; (4) mendayagunakan teknologi informasi dan komunikasi; (5) melestarikan bahan perpustakaan, baik isi maupun medianya.

Perpustakaan perguruan tinggi juga harus memiliki fungsi pendidikan, fungsi penelitian, fungsi informasi, fungsi rekreasi, dan fungsi pelestarian dalam melakukan kegiatannya. Dalam menyelenggarakan dan mengelola kegiatan perpustakaan perguruan tinggi, perpustakaan dapat memanfaatkan teknologi informasi dan komunikasi. 
Menurut Lisda Rahayu seperti yang dikutip Suharti (AD, 2020) layanan di perpustakaan memiliki hakikat untuk menyediakan segala bentuk bahan pustaka secara tepat dan akurat sesuai kebutuhan pemustaka. Di era pandemi dimana pustakawan melakukan kegiatan bekerja dari rumah dan pemustaka di perguruan tinggi juga melakukan kegiatan dari rumah, mengubah bentuk layanan perpustakaan yang dilakukan secara langsung. Perpustakaan di perguruan tinggi harus dapat menyediakan kebutuhan pemustakanya dengan memanfaatkan teknologi informasi dan komunikasi. Dengan begitu, komunikasi yang terjadi antara pustakawan dan pemustaka dimediasi oleh komputer (computer mediated communication).

\section{Computer Mediated Communication}

Komunikasi yang dimediasi oleh komputer (CMC) dapat berupa segala bentuk komunikasi yang dimediasi oleh teknologi digital. Percakapan telepon dapat dikatakan dimediasi oleh komputer jika setiap tindak tutur diubah menjadi kode digital, ditransmisikan, dan kemudian diterjemahkan untuk pendengar. Sehubungan dengan tindak tutur itu sendiri, percakapan semacam itu tidak berbeda dengan percakapan yang dimediasi oleh pertukaran telepon analog atau yang dioperasikan oleh manusia. Namun, ketika percakapan diubah menjadi bentuk yang dikelola oleh sistem komputasi, konteks teleponi spasial, temporal, dan sosial dapat diubah secara radikal. Tindak tutur dapat direkam secara digital dan dikenali secara digital dengan cara yang dapat disimpan dan dipertukarkan dengan informasi digital yang lain.

CMC atau Computer Mediated Communication secara sederhana adalah suatu bentuk komunikasi yang dilakukan oleh dua orang atau lebih melalui komputer yang berbeda. Dalam konteks CMC, komputer yang dimaksud bukan hanya sekedar personal computer namun semua alat-alat yang berbasiskan komputer seperti smartphone, tablet, PDA, dan lain-lain. Jadi email, SMS, chatting, instant messenger, merupakan bentuk CMC. Tetapi ciri yang menjadi pembeda adalah bahwa yang dimediasi adalah komunikasi, bukan informasi atau hiburan. Aktivitas utama web 1.0 seperti menjelajahi internet atau mengunduh informasi dari internet, bukan merupakan contoh CMC. Ketika di internet terjadi komunikasi antar individu, baik dari satu-ke-satu atau banyak-ke-banyak, lalu terjadinya interaksi yang melibatkan berbagi teks, suara, dan gambar, hal itulah yang merupakan contoh CMC. Bentuk CMC yang paling umum dengan bandwith sangat rendah adalah e-mail. Dalam e-mail, pengguna dapat berbagi pesan teks, gambar, dan musik. Namun, yang mendominasi dalam penggunaan e-mail tetap pesan teks. 
Sheizaf Rafaeli yang merupakan pendiri Journal of Computer-Mediated Communication merupakan salah satu ahli teori kunci yang dapat membantu kita untuk memahami interaksi dalam CMC. Dalam artikelnya di tahun 1988, Rafaeli membedakan antara konektivitas, reaktivitas, dan interaktivitas. Jaringan harus memiliki antarmuka manusia, tetapi mereka juga harus memiliki arsitektur yang memungkinkan interaktivitas. Dari jaringan interaktif seperti itu, hubungan terbentuk. Namun, bukan berarti komunikasi dua arah dapat menjamin terjadinya interaktivitas. Adanya pertukaran atau aksi-reaksi harus berkembang menjadi hubungan dimana satu ucapan menjadi konteks untuk ucapan lainnya. Tanpa bentuk konektivitas ini, hubungan menjadi melingkar atau solipsistik.

Rafaeli juga ingin meninggalkan model dyadic yang diterapkan pada kebanyakan CMC. Interaktivitas online didistribusikan di seluruh jaringan dan tidak dapat direduksi menjadi jumlah pertukaran point-to-point. Setiap pesan memperhitungkan pesan sebelumnya, serta cara pesan sebelumnya bereaksi satu sama lain. Pandangan interaktivitas ini menunjukkan bahwa penggunaan CMC yang sebenarnya jarang bersifat interaktif, terutama dalam kasus anonimitas dalam grup diskusi CMC. Perbedaan ini sesuai dengan dua arah dominan dalam penelitian $\mathrm{CMC}$ - pendekatan yang disaring isyarat, yang memfokuskan penelitian pada pengguna, dan penelitian avatar. Ketika CMC dialami sebagai perpanjangan dari hubungan interpersonal atau kelembagaan online, lawan bicara umumnya disebut sebagai pengguna. Ketika lawan bicara tidak memiliki hubungan offline dan identitas hanya ada secara online yang disebut avatar.

Penelitian tentang pengguna sangat memperhatikan cara komunikasi yang diperluas komputer yang menengahi bentuk komunikasi tatap muka. Tatap muka menjadi analog dan tolok ukur untuk mengukur "keberhasilan" CMC, yang dipandang sebagai pengganti tatap muka. Ini dikenal sebagai pendekatan yang disaring isyarat karena memeriksa isyarat komunikasi nonverbal yang hilang dalam komunikasi dan bagaimana mereka "dimasukkan kembali". Yang sangat penting untuk perspektif ini, kemudian, adalah studi tentang emotikon, simbol yang digunakan dalam email untuk menunjukkan ekspresi wajah, dan netiket, cara dunia maya menuntut bentuk protokol sopan yang diharapkan dalam kehidupan nyata.

Nancy Baym mengidentifikasi lima sumber dampak yang berbeda pada CMC: (1) konteks eksternal, di mana penggunaan CMC diatur (bahasa, kota); (2) struktur temporal grup (sinkronis atau asinkronis); (3) infrastruktur sistem komputer (kecepatan, jumlah komputer, kapasitas anonimitas, keramahan pengguna); (4) tujuan CMC digunakan 
(berorientasi minat, penggunaan dan gratifikasi); dan (5) karakteristik kelompok dan anggotanya (ukuran kelompok, tingkat pendidikan peserta).

Josh Walter di tahun 1996 mengkaji CMC dengan menggunakan tiga perspektif, yaitu impersonal, interpersonal, dan hyperpersonal. Pada perspektif impersonal, komunikasi online dianggap kurang mendukung aspek personal, karena dalam komunikasi online, sisi bahasa nonverbal tidak dapat terlihat. Kita terbiasa untuk menggunakan nada suara, mimik, dan intonasi ketika melakukan komunikasi tatap muka, dimana hal ini tidak dapat ditunjukkan dengan mudah ketika melakukan komunikasi online. Jawaban dari perspektif impersonal adalah perspektif interpersonal. Perspektif interpersonal menyebutkan bahwa dengan tidak adanya bahasa nonverbal ketika melakukan komunikasi online dapat diimbangi dengan penyesuaian sikap.

Perspektif hyperpersonal merupakan perspektif yang menganggap ketika tidak ada bahasa nonverbal ketika berkomunikasi secara online dapat membantu interaksi yang terjadi. Pada perspektif ini biasanya terjadi ketika seseorang merasa tidak nyaman ketika berkomunikasi langsung. Mereka cenderung nyaman ketika melakukan komunikasi melalui media online.

\section{Library and Knowledge Center Binus University}

Pengembangan Perpustakaan BINUS UNIVERSITY telah dirintis sejak tahun 1982 guna mendukung kegiatan Tri Darma Perguruan Tinggi, yaitu kegiatan belajar mengajar, penelitian, dan pengabdian kepada masyarakat. (Library, 2011) Perpustakaan telah mengalami beberapa kali pergantian nama seiring dengan pergantian nama perguruan tinggi itu sendiri. Nama pertama yang dipakai adalah Perpustakaan Akademik Teknik Komputer (ATK) dan menjadi Perpustakaan Sekolah Tinggi Manajemen Informatika dan Komputer BINA NUSANTARA pada tahun 1986. Nama yang hingga kini masih melekat sejak tahun 1996 adalah Perpustakaan BINUS UNIVERSITY.

Tahun 1982 adalah awal pemberian jasa kepada civitas akademika BINUS UNIVERSITY. Lokasi perpustakaan berada di Kampus Syahdan, Jl. Kh. Syahdan No. 9, Kemanggisan, Palmerah, Jakarta Barat. Jasa layanan yang diberikan menggunakan sistem manual dan tertutup (closed access services), artinya pengguna tidak dapat langsung menuju rak koleksi untuk mencari atau mendapatkan koleksi yang diinginkannya Seiring dengan perkembangan BINUS UNIVERSITY, layanan yang diberikanpun semakin berkembang. Tahun 1986 Perpustakaan berpindah tempat ke gedung M lantai dasar. Tahun 1994 Perpustakaan menempati gedung $\mathrm{K}$ dan $\mathrm{J}$, dengan sistem perpustakaan yang sudah 
terkomputerisasi (otomasi) dan menggunakan program Visual Foxpro. Sementara, layanan sirkulasi masih menggunakan sistem layanan tertutup. Bulan November 1998 perpustakaan kembali pindah menempati gedung baru di Kampus Anggrek, J1. Kebon Jeruk Raya No. 27 Jakarta Barat.

Tahun 1999 layanan perpustakaan telah terkomputerisasi dengan sistem informasi yang kemudian diberi nama Sistem Informasi Perpustakaan (SIPus). SIPus ini meliputi layanan bagian pengadaan, pengolahan, serta sirkulasi. Sistem layananpun sudah terbuka (open access sevices), sehingga mahasiswa, dosen, dan karyawan dapat mencari buku sendiri di rak. Jasa peminjaman koleksi diberikan kepada mereka yang menjadi anggota perpustakaan. Diharapkan dengan berubahnya sistem layanan, UPT Perpustakaan akan semakin dekat dengan penggunanya.

Pada September 2001, Perpustakaan The Joseph Wibowo Centre (JWC) yang berlokasi di Jalan Hang Lekir I No. 6 resmi dibuka. Perpustakaan JWC khusus melayani dosen, mahasiswa S2, dan Kelas Internasional dengan sistem layanan terbuka (open access services) dan pengembangannya masih berada dibawah koordinasi LKC Anggrek sebagai pusat LKC. Pada Agustus 2007, namanya berubah menjadi LKC - JWC Library. Layanan Intra library loan ditambahkan sebagai layanan bersama antara Circulation Anggrek dan JWC.

Perkembangan UPT Perpustakaan BINUS UNIVERSITY terus berlanjut hingga tahun 2002 dengan terus dikembangkannya SIPus dengan beberapa penambahanpenambahan layanan. SIPus yang baru saat ini sudah dapat melayani melayani penggunanya yang ingin menelusur, memesan (booking), dan memperpanjang pinjaman buku via web. Pada tahun 2006, di bawah koordinasi langsung Perpustakaan Pusat Anggrek Perpustakaan LKC Kijang berdiri. Berlokasi di area seluas 170 m2, koleksi utama dari LKC Kijang berupa buku-buku dari Jurusan sastra inggris, Cina dan Jepang dikarenakan jurusan tersebut terletak di Kampus Kijang dan sebagian besar kegiatan Fakultas Bahasa dan Kebudayaan berada di sana. LKC Kijang juga didukung oleh Self Access Language Learning Unit (SALLC) dan menempati ruangan yang sama. Mengkombinasikan koleksi cetak dan multimedia dalam kegiatan belajar telah menjadi keunggulan dari SALLC. Pada tahun 2010 SALLC menempati lokasi baru dan merubah nama menjadi Language Center. Dengan demikian LKC Kijang memiliki ruangan sendiri. Seiring bertambahnya jurusan yang ada di Kampus Kijang, yaitu Hubungan Internasional dan Hukum Bisnis koleksi LKC Kijang pun semakin bertambah. 
Pada tahun 2007, fungsi Perpustakaan Pusat Anggrek berkembang menjadi sebuah knowledge center dan kemudian berubah nama menjadi Library and Knowledge Center (LKC). Dengan fungsi baru yaitu mengakomodasi pengembangan ilmu pengetahuan dan informasi sebagai hasil proses belajar dan mengajar, serta kegiatan penelitian di Universitas Bina Nusantara.

Pada tahun 2008, LKC pindah ke lantai dasar Kampus Anggrek, menempati area seluas $\pm 1400 \mathrm{~m}^{2}$. Di gedung baru ini, LKC menyediakan ruang diskusi dan ruang rekreasi. Dengan ketersediaan akan fasilitas baru ini, pengguna Library akan mendapatkan kenyamanan lebih disaat mereka ingin belajar atau bersosialisasi demi tujuan akademis. Program Information Literacy dilakukan lebih intens dengan bantuan dari Reference Librarians dan ketersediaan Mobile Librarians yang membimbing mahasiswa secara pribadi atau berkelompok agar mereka dapat mandiri dan mampu untuk menemukan informasi dengan baik serta menggunakannya sesuai kebutuhan dan mengikuti aturan yang berlaku. Automated borrowing dan returning diimplementasikan dengan RFID system.

Pada tahun 2011 BINUS University hadir di Alam Sutera, Tangerang dengan berdirinya Bridging Campus @Alam Sutera. Pada tahun 2012 sebagai perpanjangan dari BINUS Kampus JWC, BINUS menyewa tempat di lantai 7 mall FX yang dipergunakan untuk kegiatan perkuliahan yang disertai juga dengan perpustakaan. Lalu pada September 2014 Main Campus BINUS UNIVERSITY @ Alam Sutera berdiri. Di kampus BINUS Alam Sutera ini, LKC BINUS menempati ruangan 2 lantai seluas $2.210 .65 \mathrm{~m}^{2}$

Seiring berjalannya waktu BINUS University semakin berkembang dan kampusnya semakin bertambah. Sampai dengan tahun 2021 ini, kampus BINUS University ada di 11 lokasi: Anggrek, Syahdan, Kijang, JWC, FX, Alam Sutera, Bekasi, Bandung, Malang, Semarang dan Palembang. Di setiap lokasi kecuali Palembang dan Syahdan ada LKC BINUS di dalamnya. Kampus Syahdan tidak memiliki perpustakaan karena dipusatkan di Kampus Anggrek yang jaraknya kurang lebih hanya 400 meter. Sementara itu untuk Kampus Palembang tidak ada perpustakaan karena Kampus Palembang hanya melayani perkuliahan jarak jauh.

Sebelum pandemi Covid-19 Library and Knowledge Center (LKC) BINUS University memiliki sembilan jenis layanan untuk memenuhi kebutuan informasi pemustaka secara tepat, cepat dan efisien. Layanan yang disediakan ada yang diberikan secara langsung (tatap muka), online, ataupun keduanya. Ketika pandemi berlangsung, LKC BINUS harus melakukan adaptasi untuk layanan yang dimiliki agar bisa menyesuaikan dengan kondisi yang sedang terjadi dimana LKC BINUS tidak diperkenankan menerima kunjungan 
langsung dari pemustaka. Ada beberapa layanan yang tidak bisa dilakukan, ada layanan yang tetap bisa dilakukan dengan beberapa perubahan serta ada layanan baru. Selain layanan, ada beberapa inovasi lain yang dilakukan oleh LKC BINUS agar tetap bisa berinteraksi dengan pemustakanya. Pertama penulis akan membahas layanan LKC BINUS selama pandemi Covid-19. Berikut ini layanan tersebut:

Tabel 1. Jenis layanan LKC BINUS

\begin{tabular}{|c|c|c|c|}
\hline No & Nama Layanan & $\begin{array}{c}\text { Jenis Layanan } \\
\text { Sebelum Pandemi }\end{array}$ & $\begin{array}{c}\text { Jenis Layanan } \\
\text { Saat Pandemi }\end{array}$ \\
\hline 1 & Baca di Tempat & Langsung & Ditiadakan \\
\hline 2 & Sirkulasi & Langsung & $\begin{array}{c}\text { Book Delivery } \\
\text { Services }\end{array}$ \\
\hline 3 & Referensi & $\begin{array}{c}\text { Langsung \& } \\
\text { Online }\end{array}$ & Online \\
\hline 4 & Penelusuran Informasi & Langsung & Online \\
\hline 5 & Literasi Informasi & Langsung & Online \\
\hline 6 & Silang Layan & $\begin{array}{c}\text { Langsung \& } \\
\text { Online }\end{array}$ & Online \\
\hline 7 & Penyediaan Dokumen & $\begin{array}{c}\text { Langsung \& } \\
\text { Online }\end{array}$ & Online \\
\hline 8 & Layanan Mobile & Online & Online \\
\hline 9 & Pengecekan Plagiarisme & $\begin{array}{c}\text { Langsung \& } \\
\text { Online }\end{array}$ & Online \\
\hline
\end{tabular}

Layanan baca ditempat sama sekali tidak bisa dilakukan selama pandemi berlangsung karena pemustaka sama sekali tidak diperkenankan untuk mengunjungi LKC Binus.

Sebelum pandemi melanda, layanan sirkulasi dilakukan secara langsung. Untuk peminjaman pemustaka bisa meminjam koleksi secara mandiri dengan menggunakan mesin pinjam otomatis atau melakukan peminjaman melalui petugas. Perpanjangan masa peminjaman dilakukan secara mandiri oleh pemustaka melalui website http://library.binus.ac.id/ dengan login terlebih dahulu menggunakan user ID dan password masing-masing. Untuk pengembalian dilakukan secara langsung ke petugas sirkulasi. Namun saat pandemi melanda, peminjaman koleksi beralih dengan menggunakan layanan yang dinamakan Book Delivery Services. Book delivery services merupakan layanan peminjaman dan pengembalian yang memungkinan pemustaka untuk meminjam dan mengembalikan koleksi tanpa harus datang ke perpustakaan secara langsung. Biaya pengiriman ditanggung oleh pemustaka. Dengan menggunakan layanan ini, pemustaka diharuskan untuk mengisi form secara online. Form yang digunakan adalah Form Office 
dari Microsoft. Yang bisa mengisi form tersebut hanyalah civitas akademika BINUS yang telah login menggunakan akun email Binus. Pada form ini pemustaka diminta untuk mengisi 8 pertanyaan yang terdiri dari: (1) Enter your full name; (2) Enter your Student ID/Lecturer ID; (3) Enter your phone number with Whatsapp application; (4) What kind of delivery service do you need?; (5) How do you pick up/drop off the book? (6) Location; (7) Bibli number (separate by coma for more book request) (8) Do you have read and agree of our Terms \& Conditions on Book Delivery System?

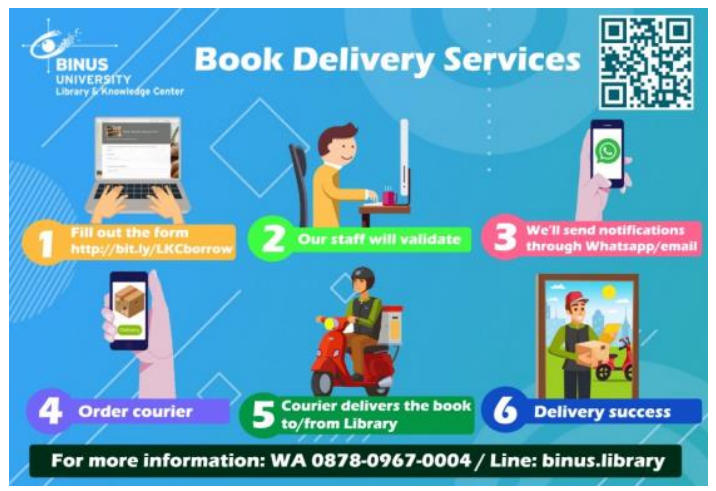

Gambar 1. Flyer promosi layanan Book Delivery Services

Pertanyaan pertama diisi dengan nama lengkap pemustaka. Pemustaka harus menggunakan nama sendiri sesuai dengan email yang digunakan.

Pertanyaan kedua pemustaka diminta mengisi nomor ID sesuai dengan statusnya, jika mahasiswa maka jumlah Idnya terdiri dari 10 digit (contoh: 2101612345). Jika dosen jumlah idnya terdiri dari 5 digit diawali dengan huruf D (Contoh: D1234).

Pertanyaan ketiga pemustaka harus mengetikkan nomor HP yang terintegrasi dengan Whatsapp. Hal ini diperlukan agar pustakawan bisa menindaklanjuti permintaan dari pemustaka.

Pertanyaan keempat pemustaka diharuskan memilih layanan yang dibutuhkan apakah peminjaman koleksi atau pengembalian koleksi.

Pertanyaan kelima pemustaka memilih cara untuk meminjam/mengembalikan buku. Pemustaka bisa memilih menggunakan kurir instan (GoSend, Grab Express, dll), menggunakan jasa pengiriman (Tiki, JNE, JnT) khusus untuk pengguna yang ingin meminjam koleksi dengan memilih jasa pengiriman maka diharuskan menggunakan JnT karena JnT memungkinkan penerima yang melakukan pembayaran. Pemustaka juga bisa memilih untuk meminjam dan mengembalikan koleksi secara drive-thru di lobi kampus. 
Pertanyaan keenam pemustaka memilih lokasi kampus dimana buku yang ingin dipinjam berada, apakah di Kampus Anggrek, Alam Sutera, Kijang, Senayan, FX atau Bekasi.

Pertanyaan ketujuh diisi mahasiswa dengan memasukan kode Bibli yaitu kode unik dari setiap judul buku yang terdaftar di LKC BINUS. Kode bibli ini bisa dilihat di website http://library.binus.ac.id/.

Pertanyaan kedelapan atau lebih tepatnya pernyataan karena pada bagian ini pemustaka diminta untuk membaca syarat dan ketentuan penggunaan layanan Book Delivery Services. Jika sudah membaca dan setuju diminta untuk mengklik "Yes" dan submit.

Setiap permintaan yang masuk akan ditindaklanjuti oleh penanggungjawab di setiap lokasi sesuai dengan lokasi dimana koleksi berada. Petugas akan terlebih dahulu mengkonfirmasi permintaan melalui Whatsapp, jika permintaan sudah sesuai maka akan segera ditindaklanjuti. Layanan Book delivery services hanya bisa dilakukan selama jam layanan yaitu Senin - Jum'at pukul 09:00 - 16.00 (kecuali hari libur). Permintaan yang masuk pada hari Sabtu, Minggu atau hari libur akan ditindaklanjuti pada hari kerja selanjutnya. Layanan referensi yang sebelum pandemi dilakukan secara langsung (tatap muka) dan online (melalui whatsapp/email) maka saat pandemi hanya bisa dilakukan secara online melalui beberapa media yaitu Whatsapp, Email, dan Zoom. Ada dua jenis layanan referensi yang disediakan oleh LKC BINUS, yaitu secara tidak langsung yang ditindaklanjuti melalui Whatsapp dan email. Secara langsung melalui Zoom. Langsung disini artinya pemustaka dan pustakawan berbicara dan berinteraksi melalui aplikasi Zoom. Layanan ini dinamakan Reference Clinic. Agar permintaan layanan referensi bisa terdata dengan baik maka disediakan form online yang harus diisi oleh pemustaka dengan login terlebih dahulu ke email BINUS. Pada form online layanan referensi tidak langsung ada 6 pertanyaan yang harus diisi, yaitu: (1) Full Name; (2) Student ID/Lecturer ID/Staff ID; (3) Mobile Phone Number with Whatsapp application; (4) Binusian's Location; (5) Type of references services; (6) Please describe your question

Pertanyaan pertama sampai ketiga sama dengan layanan Book Delivery Services, pertanyaan keempat pemustaka diminta mengisi lokasi kampus dimana pemustaka tersebut terdaftar apakah di Kampus Anggrek, Alam Sutera, Kijang, Senayan, FX atau Bekasi.

Pada pertanyaan kelima pemustaka diminta untuk memilih jenis pertanyaan referensi yang mereka butuhkan apakah mengenai buku/ebook, e-journal, e-thesis, textbook paket atau pertanyaan lain di luar 4 topik utama tersebut. 
Pada pertanyaan keenam pemustaka diminta untuk menjabarkan pertanyaan referensi mereka. Sama halnya dengan Book Delivery Service, setiap permintaan yang masuk akan ditindaklanjuti oleh pustakawan sesuai dengan lokasi pemustaka.

Pada form online layanan referensi langsung melalui Zoom (Reference Clinic) ada 8 pertanyaan yang harus diisi pemustaka, yaitu: (1) Full Name; (2) ID Binusian (3) Phone number with Whatsapp application; (4) Your Campus; (5) Your Needs; (6) Please choose date according to the topic that you choose above (7) Time; (8)I will attend the session based on the date and time that I choose.

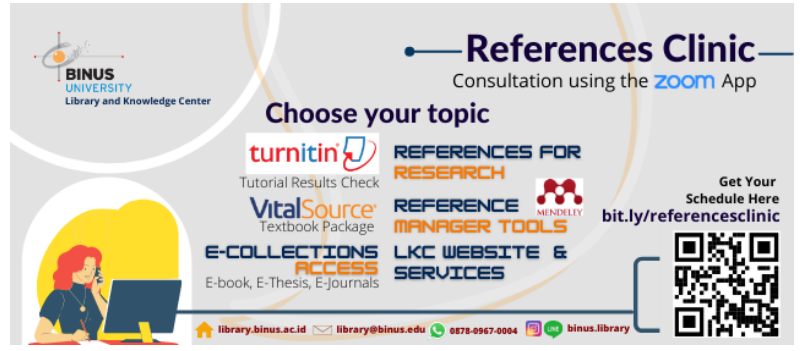

Gambar 2. E-Banner materi promosi layanan References Clinic

Pertanyaan pertama sampai keempat sama dengan layanan referensi tidak langsung, sedangkan pada pertanyaan kelima pemustaka diminta untuk memilih topik yang dibutuhkan yaitu: Turn it In, e-Textbook package, e-collections library, Reference for Research, Quotation Techniques \& Use Reference Manager Tools, How to use LKC Website, Reference service by request atau topik lain diluar topik-topik tersebut.

Pada pertanyaan keenam pemustaka diminta memilih tanggal layanan tersebut ingin dilakukan. Pada pertanyaan ketujuh pemustaka diminta memilih jam layanan yang terdiri dari : 09:00 - 11:00. 13:00 - 15:00, atau 15:00 - 17:00. Pada pertanyaan kedelapan pemustaka diminta klik "Yes" untuk kesediaan mengikuti kegiatan layanan Reference Clinic sesuai dengan tanggal dan waktu yang dipilih.

Setiap permintaan yang masuk akan ditindaklanjuti oleh pustakawan yang bertugas di minggu tersebut. Jika permintaa sudah sesuai pemustaka akan dikirim link akses Zoom untuk sesi Reference Clinic.

Layanan penelusuran informasi adalah layanan berbasis sumber informasi dari berbagai media. Pemustaka bisa minta tolong pustakawan referensi melakukan pencarian informasi yang dibutuhkan melalui berbagai jenis media yang dimiliki oleh LKC BINUS yaitu email, Whatsapp, telepon, atau media sosial. Pustakawan akan membantu mencarikan 
informasi dan setelah diklarifikasi, akan diberikan kepada pemustaka. Jenis layanan ini sifatnya impromptu dan tidak terjadwal.

Kegiatan layanan literasi informasi meliputi kegiatan bimbingan pemustaka, yaitu mahasiswa dan dosen baru untuk mengetahui lokasi, jenis koleksi, dan cara akses koleksi LKC, baik secara online maupun online. Permintaan layanan literasi informasi biasanya berasal dari jurusan atau unit lain yang ada di BINUS. Ada kegiatan literasi informasi yang sifatnya terjadwal artinya setiap tahun pasti ada yaitu kegiatan literasi informasi untuk mahasiswa baru, dosen baru dan mahasiswa tingkat akhir. Ada juga kegiatan literasi informasi yang tidak terjadwal. Biasanya permintaan tersebut berasal dari jurusan yang menginginkan mahasiswa di jurusan tersebut untuk mengikuti kelasi literasi informasi.

Pada dasarnya layanan silang layan merupakan layanan peminjaman koleksi antar kampus. Sebagai contoh mahasiswa kampus Anggrek diperbolehkan untuk meminjam koleksi kampus JWC. Mahasiswa pun diperkenankan untuk mengembalikan koleksi yang dipinjam di lokasi kampus manapun yang dikehendaki, tidak mesti di lokasi kampus dimana dia meminjam koleksi tersebut. Contoh: Mahasiswa Anggrek meminjama koleksi buku yang hanya ada di kampus JWC dan mengembalikan buku tersebut di kampus Bekasi karena rumahnya lebih dekat ke kampus Bekasi. Koleksi yang dikembalikan tidak sesuai lokasinya akan dikembalikan ke lokasi masing-masing oleh staf LKC BINUS. Selama pandemi layanan silang layan ini menggunakan layanan Book Delivery Services.

Penyediaan dokumen merupakan bagian salah satu layanan LKC BINUS yang disediakan untuk pemustaka. Bagi pemustaka yang sifatnya perorangan seperti mahasiswa atau dosen, jenis dokumen yang disediakan biasanya berupa e-articles, e-journal. Sedangkan untuk keperluan Borang LKC BINUS juga menyediakan dokumen yang dibutuhkan untuk jurusan yang akan melakukan akreditasi.

Layanan mobile pada dasarnya merupakan layanan yang dilayani oleh pustakawan melalui telfon genggam. Baik melalui Whatsapp, Line atau Media sosial. Biasanya pertanyaan-pertanyaan yang diajukan bersifat umum, seperti jam layanan, tanggal jatuh tempo pinjaman, jumlah denda, dan lain-lain. Pada saat pandemi tidak ada perbedaan dalam melakukan layanan mobile ini.

Selain layanan, ada beberapa inovasi yang dilakukan oleh LKC BINUS selama pandemi melanda. Inovasi-inovasi dilakukan agar LKC BINUS tetap bisa memberikan layanan secara maksimal kepada pemustakanya. Inovasi-inovasi tersebut yaitu: (1) Pembayaran denda menggunakan Gopay dan QRIS BCA; (2) Virtual Tour; (3) Libtalks 
Sebelum pandemi, pemustaka hanya bisa melakukan pembayaran denda menggunakan Debit BCA atau Flazz BCA. Artinya jika pemustaka memiliki denda harus datang langsung ke LKC untuk melakukan pembayaran. Dengan situasi pandemi yang tidak memungkinkan pemustaka datang langsung maka LKC berinisiatif untuk membuat jenis pembayaran denda menggunakan Gopay dan QRIS BCA. Jika pemustaka ingin membayar denda menggunakan Gopay maka pemustaka akan dikirimkan QR Code Gopay sesuai dengan lokasi kampus. Jika sudah melakukan pembayaran pemustaka diminta untuk mengunggah bukti pembayaran denda melalui form Online. Setelah dilakukan verifikasi oleh pustakawan maka pembayaran denda pemustaka tersebut akan dimasukkan ke sistem. Laporan pembayaran denda akan dikirimkan ke bagian keuangan BINUS satu bulan sekali.

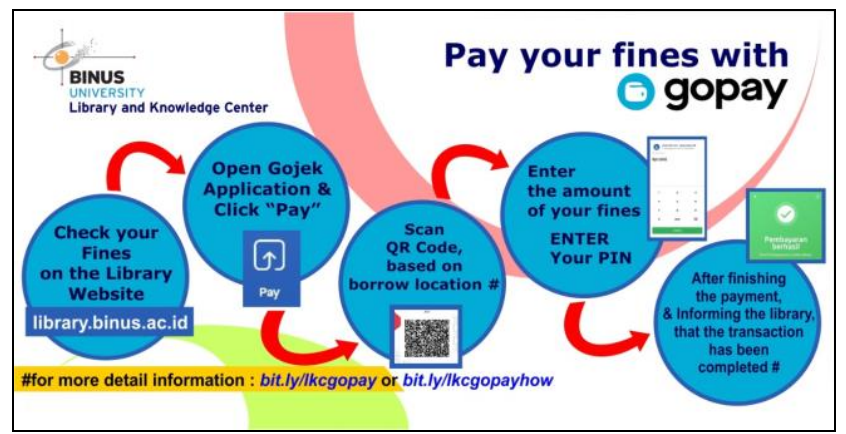

Gambar 3. e-Banner promosi Pembayaran Denda Menggunakan Gopay

Dengan hadirnya konsep Googlestreet view yang dipelopori oleh Google sebagai perusahaan di bidang teknologi informasi, memudahkan pengguna internet untuk dapat merasakan pengalaman lebih nyata saat mengunjungi berbagai tempat yang ingin dikunjungi melalui internet. Konsep sejenis juga sudah banyak digunakan oleh beberapa museum dan perpustakaan di beberapa negara maju dalam melakukan pembuatan virtual tour. LKC BINUS mengembangkan konsep $360^{\circ}$ virtual tour serupa yang dapat digunakan sebagai sarana promosi serta edukasi. $360^{\circ}$ virtual tour ini dapat berguna bagi Binusian atau siapapun yang ingin melihat fasilitas dan koleksi yang dimiliki LKC secara virtual. Selain itu, $360^{\circ}$ virtual tour ini bersifat interaktif sehingga memungkinkan pemustaka untuk dapat menggunakan layanan online yang dimiliki oleh LKC BINUS dengan cara memilih menumenu yang terdapat di $360^{\circ}$ virtual tour ini. $360^{\circ}$ virtual tour ini dapat digunakan sebagai media promosi untuk memperkenalkan LKC bagi para binusian yang baru bergabung bersama BINUS baik mahasiswa, karyawan atau dosen baru. $360^{\circ}$ virtual tour juga akan berguna dalam mendukung layanan secara online di masa seperti pandemik Covid-19 yang saat ini masih terjadi yang menyebabkan pemustaka tidak dapat mengunjungi LKC secara 
langsung. Dengan konsep virtual tour tersebut LKC BINUS membuat proyek Interactive $360^{\circ}$ virtual library. Interactive $360^{\circ}$ virtual library merupakan kumpulan video/foto interaktif yang menunjukkan gambaran fasilitas dan layanan yang dimiliki LKC BINUS secara 360 derajat. $360^{\circ}$ virtual library ini memungkinkan pemustaka untuk dapat merasakan keadaan di dalam LKC dengan melihat fasilitas-fasilitas dan koleksi yang dimiliki oleh LKC meskipun belum pernah berkunjung secara langsung.

Tidak hanya menunjukkan kondisi LKC BINUS dalam bentuk virtual saja, dalam $360^{\circ}$ virtual library ini juga terdapat beberapa menu interaktif yang dapat dipilih oleh pemustaka yang ingin menggunakan layanan online LKC BINUS ataupun sekedar mendapatkan informasi segala hal yang berkaitan dengan LKC BINUS.

Menu interaktif yang ada dalam $360^{\circ}$ virtual library ini terintegrasi dengan layanan online LKC BINUS sehingga pemustaka bisa memilih menu tersebut untuk menggunakan layanan LKC BINUS. Misalnya jika ingin melakukan layanan referensi online pemustaka bisa menuju area referensi di $360^{\circ}$ virtual library dan memilih icon layanan referensi. $360^{\circ}$ virtual library ini juga memungkinkan LKC BINUS untuk menggunggah informasi mengenai peraturan, koleksi, fasilitas, layanan dan ketentuan yang di LKC BINUS. Diantaranya informasi mengenai cara peminjaman \& pengembalian buku, denda, cara melakukan redeem ebook, daftar ebook yang dimiliki dan lain-lain. Selain itu, $360^{\circ}$ virtual library dapat digunakan juga sebagai promosi bagi LKC sebagai salah satu unit layanan di BINUS University. Promosi dapat digunakan pada saat campus tour bagi calon mahasiswa atau pengenalan BINUS University di sekolah-sekolah oleh Direktorat Marketing BINUS University. Saat ini LKC BINUS yang sudah dibuat virtual tour-nya ada 4 yaitu LKC Kampus Anggrek, LKC Kampus JWC, LKC Kampus Kijang, dan LKC Kampus Bekasi. Namun yang saat ini sudah bisa diakses secara umum adalah virtual tour LKC Kampus Anggrek. Virtual tour tersebut dapat dilihat pada link berikut ini http://library.binus.ac.id/VirtualTour/VirtualTour.aspx?modId=1\&catId=4

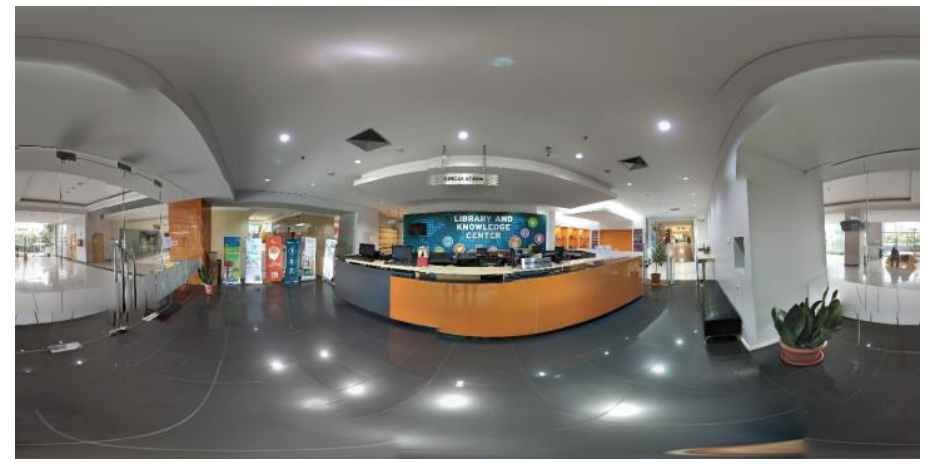

Gambar 4. Tampilan $360^{\circ}$ virtual library 
Libtalks merupakan sebuah kegiatan bincang santai yang dilakukan oleh LKC BINUS melalui Zoom dengan mengangkat tema-tema tertentu biasanya membahas mengenai buku, film atau topik-topik lain. Pembicara kegiatan Libtalks ini adalah pustakawan LKC BINUS. Namun ada saat dimana LKC BINUS mengundang pembicara professional untuk mengisi kegiatan Libtalks ini. Peserta Libtalks merupakan mahasiswa, karyawan dan dosen BINUS. Libtalks ini dibuat untuk memberikan ruang berekspresi bagi pustakawan LKC BINUS dan sekaligus interaksi dengan pemustaka.

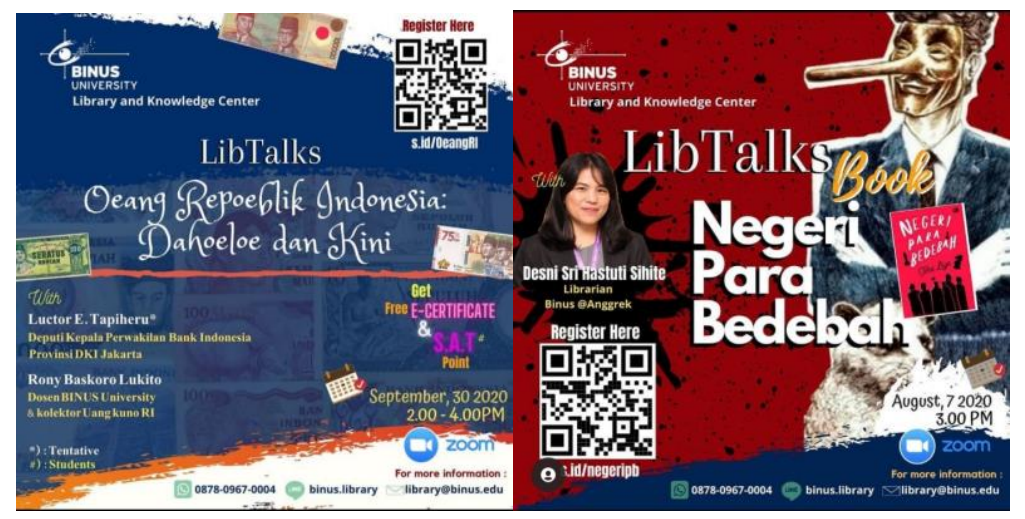

Gambar 5\&6. Promosi Libtalks

Layanan yang dilakukan di LKC BINUS University menunjukkan beberapa komunikasi yang dimediasi oleh komputer, baik secara synchronous atau asynchronous. Pada layanan seperti book delivery services, penelusuran informasi, silang layan, penyediaan dokumen, pengecekan plagiarism, dan virtual library menunjukkan kegiatan yang dilakukan dengan ruang dan waktu yang berbeda (asynchronous), sedangkan pada kegiatan referensi, literasi informasi, dan libtalks kegiatan dilakukan di ruang dan waktu yang sama (synchronous).

\section{PENUTUP}

\section{Simpulan}

BINUS University sebagai perguruan tinggi swasta dengan peringkat terbaik seIndonesia melakukan beberapa layanan virtual dan inovasi di perpustakaannya. Layanan yang dulu dilakukan secara langsung kini dilakukan pula secara online. Beberapa layanan yang kini hadir secara online diantaranya adalah layanan reference clinics, silang layan, penyediaan dokumen, dan pengecekan plagiarisme. Layanan sirkulasi berupa book delivery system juga semakin ditingkatkan di masa pandemi. LKC BINUS University juga 
melakukan beberapa inovasi pada layanannya di era pandemi. Inovasi tersebut diantaranya adalah pembayaran denda melalui Go-Pay dan QRIS BCA, adanya layanan virtual tour library, dan libtalks.

\section{Ucapan Terima Kasih}

Ucapan terima kasih disampaikan kepada Yogiswara Javmika selaku Head of Library and Knowledge Center BINUS University @Senayan Campus dan Kementrian Ristek/BRIN selaku pemberi dana.

\section{DAFTAR PUSTAKA}

AD, S. (2020). Layanan Perpustakaan Di Masa Pandemi. Buletin Perpustakaan Universitas Islam Indonesia, 3(2), 53-63.

Denzin, N. K., \& Lincoln, Y. S. (2018). The SAGE Handbook of Qualitative Research. In SAGE Publications. SAGE Publications.

Fatmawati, E. (2015). PERUBAHAN KOMUNIKASI PEMUSTAKA YANG TERMEDIASI OLEH KOMPUTER Oleh: Endang Fatmawati. Iqra' Jurnal, 09(02), $11-25$.

IFLA. (2020). Covid-19-and-Libraries @ Www.Ifla.Org. Retrieved from https://www.ifla.org/covid-19-and-libraries

Kemenkes. (2020). Tanya Jawab Coronavirus @ covid19.kemkes.go.id. Retrieved October 18, 2020, from https://covid19.kemkes.go.id/situasi-infeksi-emerging/info-coronavirus/tanya-jawab-coronavirus-disease-covid-19-qna-update-6-maret2020/\#.X4xpMWgzbIU

Kurnia Firmansyah, E., \& Dyah Putrisari, N. (2017). Sistem Religi Dan Kepercayaan Masyarakat Kampung. Jurnal Pengabdian Kepada Masyarakat, 1(4), 236-243.

Library, B. (2011). History @ library.binus.ac.id. Retrieved from http://library.binus.ac.id/About Us/History.aspx?modId=1\&catId=3

Margareta, S. (2013). Study Deskriptif Analisis Kuantitatif. Repository UPI.

Perpusnas. (2017). Peraturan Kepala Perpustakaan Nasional RI No 13 tahun 2017. Perpusnas. Jakarta: Perpusnas.

Suharso, P., Arifiyana, I. P., \& Wasdiana, M. D. (2020). Layanan perpustakaan perguruan tinggi dalam menghadapi pandemi covid-19. Anuva, 4(2), 271-286. Retrieved from https://ejournal2.undip.ac.id/index.php/anuva/article/view/8185/4303 
Webometrics. (2021). indonesia @ www.webometrics.info. Retrieved May 17, 2021, from https://www.webometrics.info/en/asia_es/indonesia?sort=asc\&order=World Rank WHO. (2021). WHO Coronavirus Disease (COVID-19) Dashboard @ covid19.who.int. Retrieved May 17, 2021, from https://covid19.who.int/table 